Article

\title{
An Analysis Model Combining Gamma-Type Stirling Engine and Power Converter
}

\author{
Hua-Ju Shih
}

Institute of Applied Mechanics, National Taiwan University, Taipei 10617, Taiwan; d04543001@ntu.edu.tw; Tel.: +886-2-3366-5600

Received: 18 February 2019; Accepted: 5 April 2019; Published: 6 April 2019

check for updates

\begin{abstract}
Waste heat is a potential source for powering our living environment. It can be harvested and transformed into electricity. Ohmic heat is a common type of waste heat. However, waste heat has the following limitations: wide distribution, insufficient temperature difference $(\Delta T<70 \mathrm{~K})$ for triggering turbines, and producing voltage below the open voltage of the battery. This paper proposes an energy harvester model that combines a gamma-type Stirling engine and variable capacitance. The energy harvester model is different from Tavakolpour-Saleh's free-piston-type engine [7.1 W at $\Delta T=407 \mathrm{~K}(273-680 \mathrm{~K})]$. The gamma-type Stirling engine is a low-temperature-difference engine. It can be triggered by a minimum $\Delta T$ value of $12 \mathrm{~K}$ (293-305 K). The triggering force in the variable capacitance is almost zero. Furthermore, the gamma-type Stirling engine is suitable for harvesting waste heat at room temperature. This study indicates that $21 \mathrm{~mW}$ of energy can be produced at $\Delta T=30 \mathrm{~K}(293-323 \mathrm{~K})$ for a bias voltage of $70 \mathrm{~V}$ and volume of $103.25 \mathrm{cc}$. Because of the given bias voltage, the energy harvester can break through the open voltage of the battery to achieve energy storage at a low temperature difference.
\end{abstract}

Keywords: gamma-type Stirling engine; energy harvester; variable capacitance; low-temperature difference engine

\section{Introduction}

Many forms of waste heat are produced in our living environment, such as the heat of combustion from factories, ohmic heating of computers, and heat from compressors. These heat sources increase the ambient temperature and cause global warming if we not do suitably handle them. Common methods of waste heat recovery include turbocharging, turbocompounding, thermoelectrics, and cabin heating and cooling [1]. Therefore, waste heat should be harvested and stored as electric power. The most suitable method for achieving this objective involves thermoelectric material use. However, the costs of semiconductor thermoelectric material are too high for typical thermoelectric power generation applications at $\Delta T<135^{\circ} \mathrm{C}$ [2]. This study aims to convert heat into electric power. To achieve this target, there exist three procedures. The first procedure involves converting heat into mechanical energy, the second involves converting mechanical energy into electric energy, and the third involves a combination of first two procedures. The three procedures are discussed in the following text.

The Stirling engine, which was created by Robert Stirling in 1816, has high efficiency for transforming heat into mechanical energy [3]. The Stirling cycle involves the cyclic expansion and compression of the working fluid by maintaining a temperature difference between the hot and cold plates. The heat energy produced can be converted to mechanical work. Stirling engines can be classified into three types: alpha, beta, and gamma machines [4]. The alpha-type Stirling engine has two pistons for compression and expansion. Both pistons are connected to the same crankshaft. The beta-type Stirling engine has one piston and one displacer, which share the same air room. The piston and displacer are linked by a wheel with two crankshafts. In the gamma-type engine, the piston and 
displacer are housed within two air rooms. The gamma-type engine (low temperature difference (LTD) engine) is the most suitable option for triggering the Stirling engine with a temperature difference from the environment $\left(\Delta T=10-30^{\circ} \mathrm{C}\right)$ [4]. The gamma-type engine has a high rotating speed, is triggered at LTDs, and has a small torque. The rotating speed is inversely proportional to the torque [5].

To calculate the performance of the Stirling engine, researchers developed computer fluid dynamic modes in commercial software [6]. Robson et al. created a dynamic model which forms with each motion of component [7]. Egas and Clucas compared the net work values of five types of Stirling engines by using the thermodynamics model [4]. Abovementioned studies have assumed that the instantaneous pressure in a Stirling engine is constant. However, a variety of instantaneous pressures should be considered in reality. Kim et al. used thermal flow to analyze high and low pressures in an LTD Stirling engine [8].

For transforming mechanical energy to electrical energy, a conversion method that affects the mechanism of harvester should be selected. Vibration energy harvesters (VEHs) can be classified into three types according to the principle of electron transfer: (i) electrostatic, (ii) electromagnetic, and (iii) piezoelectric VEHs. The electromagnetic method is unsuitable for microelectromechanical systems because the magnetic coil requires complicated manufacturing processes [9]. The piezoelectric material is highly brittle and hence is limited to a small deflection range [10]. In the electrostatic method, a bias voltage is provided between two metal plates so that they become a capacitance component. The capacitance component then releases current from the elevated potential energy through vibration [11]. The electrostatic method is more convenient than the electromagnetic and piezoelectric methods for harvesting energy from the environment. The capacitance component can be manufactured in any geometric shape and size to maximize the capacitive value. The component is widely used to increase the overlap area between two electrodes in the design concept of the interdigitated electrode [12,13]. Moreover, the designer adjusts the resonance frequency of the VEH according to the vibration source [14]. In addition to changing the gap of the variable capacitance, Moon et al. build a reverse electrowetting device with changing overlap area [15]. Hsu et al. proposed the bubbler structure, which causes air bubbles to move into the gap between two electrodes. The entry of air bubbles changes the dielectric coefficient of the variable capacitance [16].

Energy harvesting and storage can be achieved at room temperature. Some researchers select the vibrations of pavements, which are caused by human walking and car movement $[17,18]$. The frequency of human walking is $1.41-2.13 \mathrm{~Hz}$ [19], and the frequency of bridge vibration is $0-30 \mathrm{~Hz}$ [20]. The vibration source should have a high frequency, provide continuous waves, and have a stable amplitude for VEHs. The vibration source above has a low frequency (resonance frequency of the capacitive VEH is 6-13 GHz [21]), is discontinuous, and is unstable. Consequently, the vibration source is unsuitable for the electrostatic method. Therefore, the gamma-type Stirling engine can provide a stable and high-frequency source for capacitive VEHs. The bias voltage from the harvester can break through the open circuit voltage of the battery (open circuit voltage of lithium-ion batteries is 2.7-3.6 V during the charging process [22]). The Stirling generator has many applications. To accelerate the free-piston Stirling engine for reaching the resonance state $(9.2 \mathrm{~Hz})$, Tavakolpour-Saleh et al. [23] installed an additional DC motor on the Stirling engine. The obtained output power was $7.1 \mathrm{~W}$ at $\Delta T=407 \mathrm{~K}(273-680 \mathrm{~K})$. The combined heat and power system is an efficient energy recovery system. It can generate electricity and useful thermal energy and provide warm bath water, warm air, and electricity $(10-36 \mathrm{~kW})$ in the house [24,25]. The dish Stirling generator can obtain solar energy through a concentrator and reflector. The range of output obtained with this generator is $2-50 \mathrm{~kW}$. The dish Stirling generator is built in the United States, Japan, and Russia [26].

A mathematical model is proposed for evaluating the performance of the gamma-type Stirling engine with a capacitive harvester $(\mathrm{GSCH})$. The governing equation of the energy harvester is constituted according to the conservation of energy. The governing equation includes the heat transfer, dynamic model, and electric model. If a temperature difference is applied between the hot plate and cold plate in the GSCH (input), the heat energy from the hot plate enters the work system of 
the Stirling engine. The energy is assigned into three parts, namely the mechanical, air, and friction parts. The mechanical part provides mechanical energy to generate power (output). According to the simulation results, the wheel of the energy harvester has a rotation frequency of $3.35 \mathrm{~Hz}$ at $\Delta T=30 \mathrm{~K}(298-328 \mathrm{~K})$ and can produce $21 \mathrm{~mW}$ electric power under unit area at a bias voltage of $70 \mathrm{~V}$. Moreover, the optimized size of the engine can be determined by changing the geometric shape and size of the gamma-type Stirling engine, which has maximum conversion efficiency in a specific temperature range.

\section{Modeling}

\subsection{Heat Transfer}

We assume that the temperature function of the GSCH only depends on the distance of the $z$-axis. The heat transfer model can be simplified by considering an ideal cylinder. Consider that the thermal conductivity (ignoring convection and radiation) and temperature have a linear relationship. Therefore, the heat transfer rate is $q$ (Figure 1). The heat transmitted through the hot plate, air room, and cold plate can be written as follows:

$$
q=\frac{T_{1}-T_{4}}{\frac{\Delta z_{\text {Hot }}}{k_{\text {Hot }} A_{D c}}+\frac{\Delta z_{A i r}}{k_{A i r} A_{D c}}+\frac{\Delta z_{C o l d}}{k_{\text {Cold }} A_{D c}}}
$$

where $\Delta z_{H o t}, \Delta z_{A i r}$, and $\Delta z_{H o t}$ are the thicknesses of the hot plate, air room, and cold plate, respectively, and $A_{D c}$ the cross-sectional area of the air room.

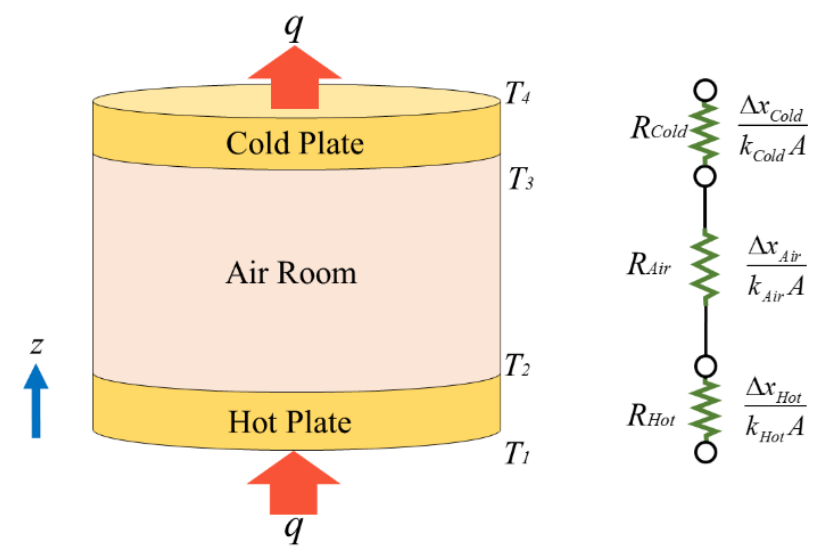

Figure 1. One-dimensional heat transfer (conduction only) through the GSCH and electrical analog.

The thermal conductivity of the hot $\left(k_{\mathrm{Hot}}\right)$ and cold $\left(k_{\mathrm{Cold}}\right)$ plates can be obtained easily. However, the rigorous theory for the determination of the thermal conductivity of the air room does not exist. A forced convection enclosed flow field occurs in the air room of the Stirling engine. In this study, the heat transfer contribution of the displacer was not considered. The empirical relations for free convection are provided in the enclosures [27].

\subsection{Kinematics}

Figure 2 displays the major components and strokes of the gamma-type Stirling engine. The displacement functions of the piston and displacer are represented using the angular displacement of the engine shaft as follows:

$$
\begin{aligned}
& z_{p}=\frac{L_{p}}{2}\left[1+\cos \left(\theta-\frac{\pi}{2}\right)\right], \\
& z=\frac{L}{2}[1+\cos \theta]
\end{aligned}
$$


where $z_{p}$ and $z$ are the vertical positions of the piston and displacer, respectively, and $\theta$ the rotation angle of the shaft. The displacer is in its highest position $(z=L)$ for at $\theta=0$. The phase difference between the movements of the displacer and piston is $\pi / 2$.

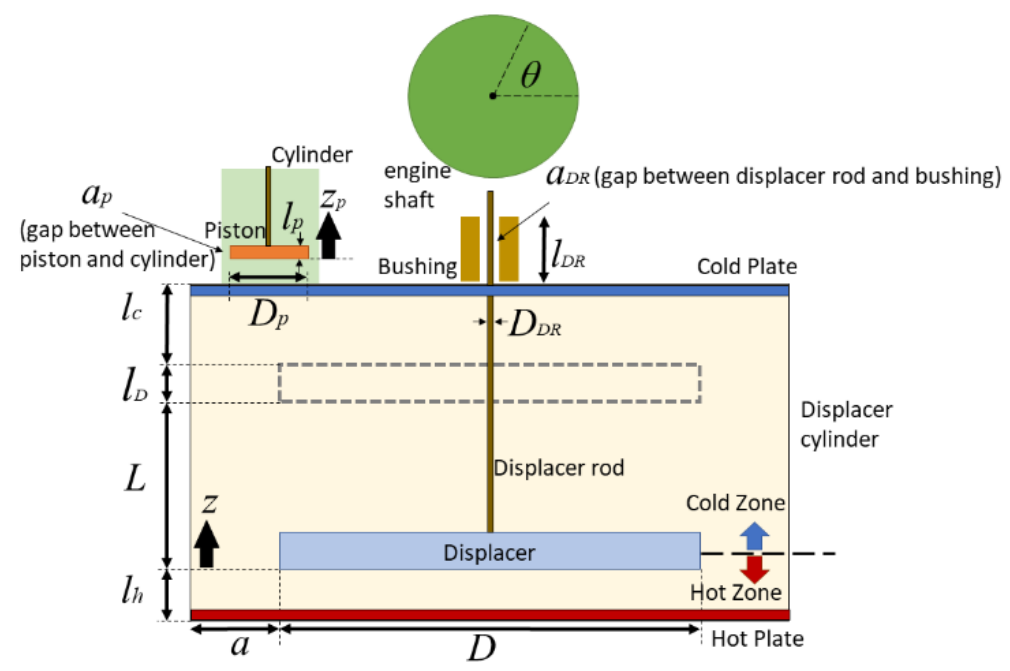

Figure 2. Nomenclature and major components of the gamma-type Stirling engine.

The displacer and piston perform periodical vertical movement when the Stirling engine functions with an angular velocity $\omega$. The relationships between the vertical movement of the piston and displacer and the angular velocity are given as follows:

$$
\begin{aligned}
& U_{z}=-\frac{L}{2} \cdot \sin \theta \cdot \omega, \\
& U_{z p}=-\frac{L p}{2} \cdot \sin \left(\theta-\frac{\pi}{2}\right) \cdot \omega .
\end{aligned}
$$

Therefore, the Stirling engine performs three functions: (i) gas compression and expansion, (ii) mechanical motion, and (iii) friction loss when the engine is running. According to the first law of thermodynamics, the work of engine is given as follows:

$$
W_{\text {eng }}=W_{\text {gas }}+W_{\text {mech }}+W_{\text {loss }}
$$

where $W_{\text {gas }}$ and $W_{\text {mech }}$ are the work of the gas and mechanical component, respectively, and $W_{\text {loss }}$ the work of friction loss.

\subsection{Gas Work}

The source of power of the Stirling engine is the pressure gradient in air room, which is formed because of the difference in the temperature of the cold and hot plates. In this section, we refer to the method of Kim et al. to calculate the gas work of the Stirling engine [8]. Because of the low speed and small size of the gamma-type Stirling engine, the airflow in the air room can be reasonably assumed to be laminar. Moreover, at 10 RPS, the maximum Reynolds number is 985 as per the mean velocity and hydraulic diameter for the flow through the annulus between the displacer and air room wall. The air room comprises a compression space $\left(V_{h D}+V_{h d}\right)$ and an expansion space $\left(V_{c D}+V_{c d}\right)$, as displayed in Figure 3. 


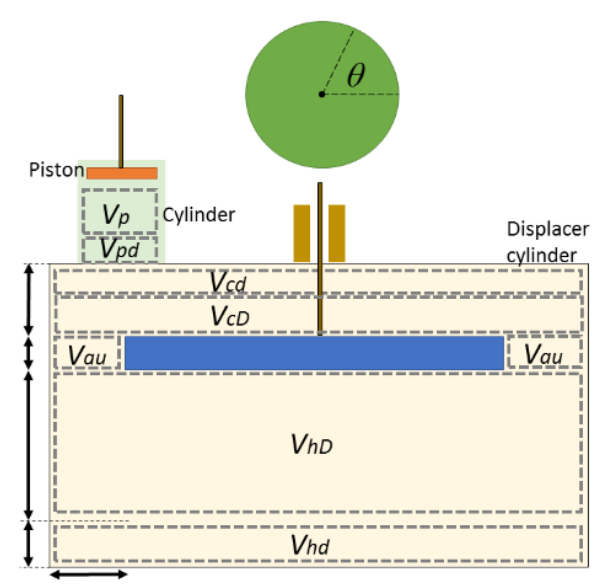

Figure 3. Volumes in thermal flow of the gamma-type Stirling engine.

In Figure $3, V_{h D}$ and $V_{c D}$ change with the displacer movement and $V_{p}$ changes with the piston movement. These relationships are expressed as follows:

$$
\begin{aligned}
& V_{h D}=A_{D c} \cdot \frac{L}{2}(1+\cos \theta), \\
& V_{c D}=A_{D c} \cdot\left[L-\frac{L}{2}(1+\cos \theta)\right], \\
& V_{p}=A_{p} \frac{L_{p}}{2}\left[1+\cos \left(\theta-\frac{\pi}{2}\right)\right],
\end{aligned}
$$

where $A_{D c}$ and $A_{p}$ are the cross-sectional area of the air room and piston, respectively. The rate of airflow from the compression space to the expansion space depends on the pressure gradient across the displacer and the viscous force on the lateral surface of the displacer. According to approximation, the flow rate of the flow passing the annulus of the displacer is given as follows:

$$
Q_{v}=\pi D\left(\frac{U_{z} a}{2}-\frac{1}{12 \mu} \frac{d p}{d z} a^{3}\right)=-A_{D c} U_{z}
$$

where $\mu$ is the dynamic viscosity of air. Through Equation (6), the pressure gradient in the displacer annulus written as follows:

$$
\frac{d p}{d z}=\frac{6 \mu L}{\pi D a^{3}}\left(A_{D c}+\frac{\pi D a}{2}\right) \sin (\theta) \omega .
$$

We assume that the pressure gradient in the displacer annulus can be approximated using the following equation:

$$
\frac{d p}{d z} \simeq \frac{p_{c}-p_{h}}{l_{D}}
$$

where $p_{c}$ and $p_{h}$ are the pressure of the cold and hot regions in the air room, respectively. The relationship between the cold and hot pressure is given as follows:

$$
p_{h} \simeq p_{c}+\frac{6 \mu L}{\pi D a^{3}}\left(A_{D c}+\frac{\pi D a}{2}\right) l_{D} \sin (\theta) \omega .
$$

The gas in the air room is assumed to be an ideal gas, and no air is assumed to leak. The value of $p_{c}$ depends on the geometry of the air room, temperature, rotation angle of the shaft, angular velocity, dynamic viscosity of air, and gas constant.

$$
p_{c}=\frac{M-\left[\left(a_{6}+a_{9}\right) \sin (\theta) \omega+a_{7} \cos (\theta) \sin (\theta) \omega\right]}{a_{1}+a_{4}+a_{8}+\left(a_{2}+a_{5}\right) \cos (\theta)+a_{3} \cos \left(\theta-\frac{\pi}{2}\right)},
$$


where $M$ is the total mass of air in the air room and $a_{1}-a_{9}$ the coefficients of the Stirling engine (Table A2). Therefore, the gas work of the Stirling engine per cycle is given as follows:

$$
\begin{aligned}
& W_{g a s}=W_{p p}+W_{p d} \\
& =\int p_{c} A_{p} d z_{p}+\int A\left(p_{c}-p_{h}\right) d z \\
& =-\frac{L_{p}}{2} \int_{0}^{2 \pi} A_{p} p_{c} \sin \left(\theta-\frac{\pi}{2}\right) d \theta-\frac{L}{2} \int_{0}^{2 \pi} A\left(p_{c}-p_{h}\right) \sin (\theta) d \theta,
\end{aligned}
$$

where $W_{p p}$ and $W_{p d}$ are the moving-boundary work produced by the piston and displacer per cycle, respectively.

\subsection{Mechanical Component Work}

The engine work comprises three components, namely the work of the (i) flywheel, (ii) shaft assembly, and (iii) piston and displacer systems. The work of the engine is represented as follows:

$$
W_{\text {mech }}=W_{\text {wheel }}+W_{\text {shaft }}+\left(W_{\text {dis }}+W_{\text {pis }}\right),
$$

where $W_{\text {wheel }}$ is the work of the flywheel, $W_{\text {shaft }}$ the work of the shaft, $W_{\text {dis }}$ the work of the displacer system, and $W_{\text {pis }}$ the work of the piston system. As shown in Figure 4a, there exist two holes in the first quadrant of the flywheel. The two holes cause the center of mass to be located in the third quadrant. Therefore, the work of the flywheel is written as follows:

$$
\begin{aligned}
& W_{\text {wheel }}=M_{\text {wheel }} \cdot g \cdot Z_{\text {wheel }}+0.5\left(0.5 M_{\text {wheel }} R_{\text {wheel }}^{2}+M_{\text {wheel }} R_{\text {new }}^{2}\right) \omega^{2}, \\
& Z_{\text {wheel }}=R_{\text {new }}[1+\cos (\theta+1.5 \pi)],
\end{aligned}
$$

where $M_{\text {wheel }}$ is the mass of the flywheel, $g$ the gravity, $R_{\text {new }}$ the distance between the center of the flywheel and mass of the center point, and $Z_{\text {wheel }}$ the vertical distance (when $\theta=1.5 \pi, Z_{\text {wheel }}$ is maximum). Moreover, a bearing links the rotation of the shaft and flywheel (Figure 4a). The work of the shaft is written as follows:

$$
W_{\text {shaft }}=0.5\left(M_{c} R_{c}^{2}+2 M_{s} R_{s}^{2}\right) \omega^{2},
$$

where $M_{c}$ and $M_{s}$ are the mass of the bearing and shaft, respectively, and $R_{c}$ and $R_{s}$ the radii of the bearing and shaft, respectively.

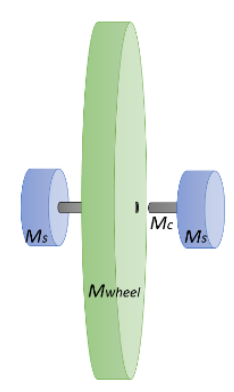

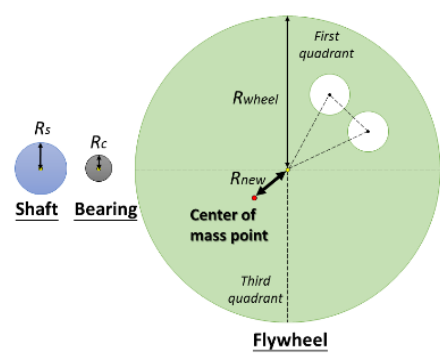

(a)

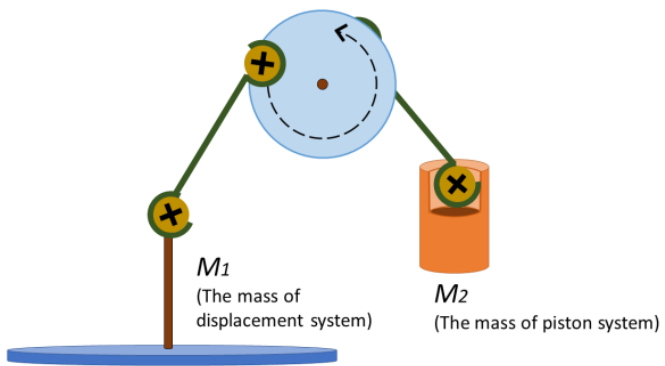

(b)

Figure 4. Nomenclature and major components of flywheel power systems. (a) The shafts, bearing, and flywheel; (b) The $M_{1}$ and $M_{2}$ systems. 
For convenient calculation, all the components (displacer, piston, screws, and links) are set up in two mass systems: displacer and piston systems (Figure $4 \mathrm{~b}$ ). The work of the displacer and piston systems is then given as follows:

$$
\begin{aligned}
& W_{\text {dis }}=M_{1} \cdot g \cdot z+0.5\left(M_{1} U_{z}^{2}\right), \\
& W_{\text {pis }}=M_{2} \cdot g \cdot z+0.5\left(M_{2} U_{z p}^{2}\right)
\end{aligned}
$$

where $M_{1}$ and $M_{2}$ are the mass of the displacer and piston systems, respectively. As indicated by Equations (12)-(15), the work of the engine depends on the angular velocity of the engine.

\subsection{Friction Loss}

The work of friction falls into two broad categories: solid and gas friction loss. Among them, solid friction loss occurs at contact surfaces between the bearing and shafts. Furthermore, the volume of solid friction depends on the torque acting on the bearing. The work of friction in one cycle can be represented as follows:

$$
\begin{aligned}
\Omega_{\text {shaft }}= & \mu_{k} \cdot \tau_{\text {shaft }} \cdot V_{\text {tan }} \cdot \mathrm{T}_{\text {per }} \\
= & 2 \pi f \mu_{k}\left(\left|F_{\text {piston }}\right|+\left|F_{\text {displacer }}\right|\right) R_{c} \cdot \mathrm{T}_{\text {per }} \\
& =-\left(\pi \mu_{k} R_{c} L\right)\left\{\omega^{2}\left[\left|M_{1} \int_{0}^{2 \pi} \cos \theta d \theta\right|+\left|M_{2} \int_{0}^{2 \pi} \cos \left(\theta-\frac{\pi}{2}\right) d \theta\right|\right]\right. \\
& \left.\quad+\alpha\left[\left|M_{1} \int_{0}^{2 \pi} \sin \theta d \theta\right|+\left|M_{2} \int_{0}^{2 \pi} \sin \left(\theta-\frac{\pi}{2}\right) d \theta\right|\right]\right\},
\end{aligned}
$$

where $\mu_{k}$ is the coefficient of kinetic friction, $\tau_{\text {shaft }}$ the load, $V_{\text {tan }}$ the tangential velocity of the shaft, $T_{\text {per }}$ the period, $f$ the frequency, and $\alpha$ the angular acceleration.

The method of [8] is used to analyze the work of gas friction loss. The analytical method is applicable for (i) steady flow, (ii) incompressible laminar flow, and (iii) completely developed flow in the air room. The shear stresses on the lateral surfaces of the displacer, piston, and displacer rod are given as follows:

$$
\begin{aligned}
& \tau=\mu \frac{U_{z}}{a}+\frac{a}{2} \frac{d p}{d z}, \\
& \tau_{p}=\frac{\mu U_{z p}}{r_{p} \ln \left(\frac{r_{p}}{r_{p}+a_{p}}\right)}, \\
& \tau_{D R}=\frac{\mu U_{z}}{r_{D R} \ln \left(\frac{r_{D R}}{r_{D R}+a_{D R}}\right)} .
\end{aligned}
$$

Equation (17) is applied to obtain the work of friction loss from the viscous drags in the displacer, piston, and displacer rod per cycle.

$$
\begin{aligned}
& \Omega_{s}=\int F_{s} d z=-\frac{L}{2} \int_{0}^{2 \pi} \pi D l_{D} \tau \sin (\theta) d \theta \\
& \Omega_{s p}=\int F_{s p} d z_{p}=-\frac{L_{p}}{2} \int_{0}^{2 \pi} \pi D_{p} l_{p} \tau_{p} \sin \left(\theta-\frac{\pi}{2}\right) d \theta \\
& \Omega_{s D R}=\int F_{s D R} d z=-\frac{L}{2} \int_{0}^{2 \pi} 2 \pi r_{D R} l_{D r} \tau_{D R} \sin (\theta) d \theta .
\end{aligned}
$$

where $F_{s}, F_{s p}$, and $F_{s D R}$ are the shear forces on the lateral surfaces of the displacer, piston, and displacer rod, respectively.

By integrating Equations (18), the relationship between the temperature difference $\left(\Delta T=T_{1}-T_{4}\right)$ and the frequency of the gamma-type Stirling engine movement can be obtained:

$$
\begin{aligned}
& q \cdot T_{\text {per }}=W_{\text {eng }} \\
& \Rightarrow \Delta T=c_{1} f^{3}+c_{2} f^{2}+c_{3} f,
\end{aligned}
$$

where $c_{1}, c_{2}$, and $c_{3}$ are functions such as the mass, geometry, angle, force, kinetic friction coefficient, and dynamic viscosity (Table A1). 


\subsection{Electrostatic Capacitance}

The capacitive energy harvester consists of two electrode plates: piston and piston cylinder (Figure 5). According to the capacitive formula, the capacitance value is proportional to the overlap area of the two electrode plates and the frequency of engine rotation. Therefore, changes in the capacitance value depend on the Stirling engine movement.

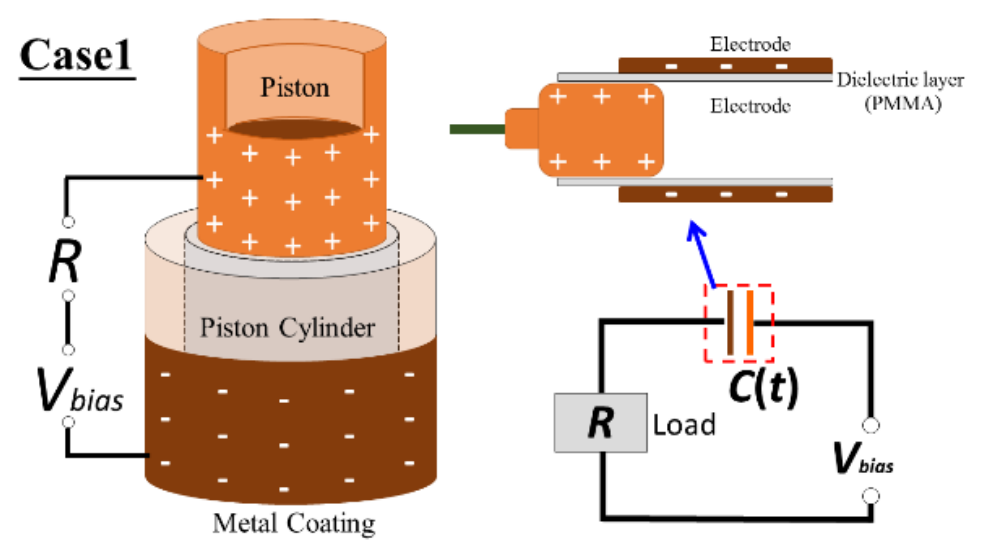

Figure 5. Schematic and equivalent circuit diagram of energy harvesters.

Krupenkin and Taylor proposed a method to simulate the energy harvester with periodic movement [28]. The equivalent circuit is displayed in Figure 5. The circuit has a bias voltage of $V_{\text {bias }}$, resistive load of $R$, and variable capacitance of $C$. According to Kirchhoff's circuit laws, the RC (resistance and capacitance) circuit is represented as follows:

$$
\begin{aligned}
& \frac{d Q_{c}}{d t}+\frac{Q_{c}}{R C}-\frac{V_{\text {bias }}}{R}=0, \\
& Q_{c}(t=0)=V_{\text {bias }} C_{0},
\end{aligned}
$$

where $Q_{c}$ is the charge on the variable capacitor, $C_{0}$ the maximum capacitance of the variable capacitor, $V_{\text {bias }}$ the bias voltage, and $t$ the time. The variation in the capacitance with time is expressed as follows:

$$
\begin{aligned}
& C(t)=0.5 C_{0}(1+\cos (\omega t)), \\
& C_{0}=\frac{\varepsilon_{0} k_{\text {die }} A_{\text {over }}}{h},
\end{aligned}
$$

where $A_{\text {over }}$ is the maximum overlap area between the outer part of the piston surface and the piston cylinder during the Stirling engine cycle, $h$ the dielectric thickness of the piston cylinder, $k_{\text {die }}$ the dielectric constant of the thin film, and $\varepsilon_{0}$ the vacuum permittivity.

Equation (20) is transformed into a dimensional equation as follows:

$$
\begin{aligned}
& a_{0} \frac{d \hat{Q}_{c h}}{d \hat{t}}+\frac{2 \hat{Q}_{c h}}{1+\cos \hat{t}}-1=0, \\
& \hat{Q}_{c h}(\hat{t}=0)=1,
\end{aligned}
$$

where $\hat{Q}_{c h}=Q_{h} V_{\text {bias }}^{-1} C_{0}^{-1}, a_{0}=\omega R C_{0}$, and $\hat{t}=\omega t$. The solution of Equation (22) is given as follows:

$$
\hat{Q}_{c h}=\frac{1}{a_{0}} e^{-\frac{z i}{a_{0}}-\frac{z \tanh \left[\frac{t}{2}\right]}{a_{0}}}\left(a_{0} e^{\frac{z i}{a_{0}}}+i e^{\frac{4 i}{a_{0}}} \operatorname{Ei}\left[-\frac{2 i}{a_{0}}\right]-i E i\left[\frac{2 i}{a_{0}}\right]-i e^{\frac{4 i}{a_{0}}} \operatorname{Ei}\left[\frac{2\left(-i+\tanh \left[\frac{t}{2}\right]\right)}{a_{0}}\right]+i \operatorname{Ei}\left[\frac{2\left(i+\tanh \left[\frac{t}{2}\right]\right)}{a_{0}}\right]\right),
$$


where $\operatorname{Ei}(x)=-\int_{-x}^{\infty} \frac{e^{-j}}{j} d j$ is an exponential integral. The energy harvested per Stirling engine cycle is expressed as

$$
\hat{E}=\int_{\text {period }} a_{0}\left(\frac{d \hat{Q}_{c h}}{d \hat{t}}\right) d \hat{t} \simeq \frac{5}{4}\left[1-\tanh \left(0.5\left(1-\log \left(a_{0}\right)\right)\right],\right.
$$

and Equation (24) can be written with the original variables as follows:

$$
E=\frac{5}{4} V_{\text {bias }}^{2} C_{0}\left[1-\tanh \left(0.5\left(1-\log \left(\omega R C_{0}\right)\right)\right] .\right.
$$

Therefore, the average generated power is given as follows:

$$
P=\frac{5}{4} V_{\text {bias }}^{2} C_{0} T^{-1}\left[1-\tanh \left(0.5\left(1-\log \left(\omega R C_{0}\right)\right)\right] .\right.
$$

\section{Result and Discussion}

The temperature difference is used to change the volume of the air room, which in turn induces a change in the piston position. As indicated by Equation (5), the sizes of the compression space $\left(V_{h D}+V_{h d}\right)$ and expansion space $\left(V_{c D}+V_{c d}\right)$ depend on the phase angle of the wheel. In a gamma-type Stirling cycle, the isothermal compression is $\theta=13 \sim 3(\pi / 8)$, constant volume heating is $\theta=4(\pi / 8)$, isothermal expansion is $\theta=5-11(\pi / 8)$, and constant volume cooling is $\theta=12(\pi / 8)$. When $\theta=4(\pi / 8)$, the air room has maximum volume. The pressure difference between the hot and cold regions varies with the sinusoid motion of the displayer at fixed temperature differences (Figure 6). The variations in $p_{h}$ and $p_{c}$ for $\theta=1-4(\pi / 8), \theta=9-12(\pi / 8)$, and $\Delta T=0-30 \mathrm{~K}$ are calculated using Equations (9) and (10), where $\omega=2 \pi f$ for each $\Delta T$ is the result obtained from Equation (19). The relative pressure (compared with atmospheric pressure) of the cold region is 2921.8-2985.7 Pa for $\theta=\pi / 2$.

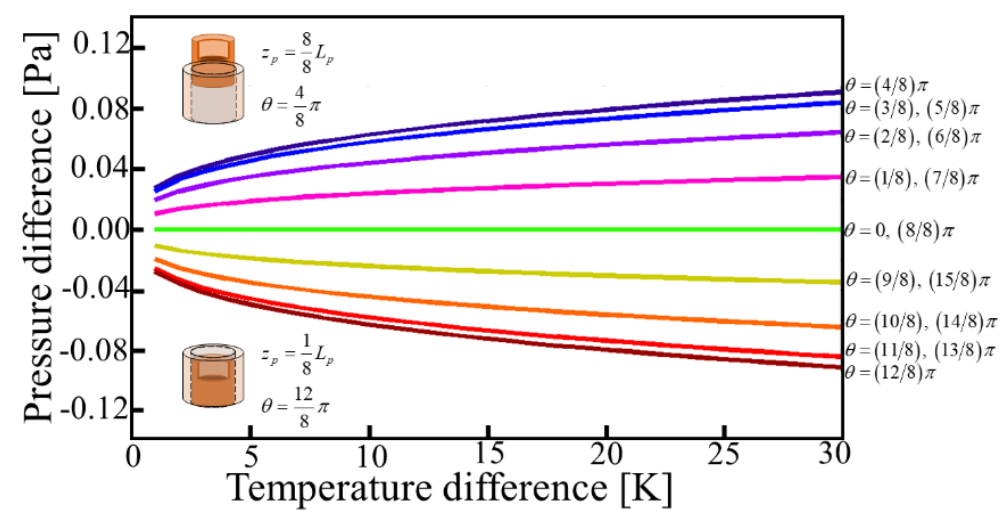

Figure 6. Pressure difference lines $\left(\Delta p(\theta)=p_{h}(\theta)-p_{c}(\theta)\right)$ in the air room at different $\theta$ values for different temperature differences between the cold and hot regions of the Stirling engine $\left(T_{4}=293 \mathrm{~K}\right.$, $T_{1}=293-323 \mathrm{~K}$ ).

The pressure difference in the air room of the gamma-type Stirling engine is very small because the thickness of the air room is only $10 \mathrm{~mm}$. Consequently, hot and cold air mix quickly in the air room. Thus, the Stirling engine works in a steady state, which only requires a pressure difference of less than $0.1 \mathrm{~Pa}$ in the air room.

The relationship between the temperature differences of the Stirling engine and the frequency of the wheel can be obtained using Equation (19). Assume that the cold and hot plates have an initial temperature of $293 \mathrm{~K}(\Delta T=0 \mathrm{~K})$ and the hot plate is then heated to $323 \mathrm{~K}(\Delta T=30 \mathrm{~K})$. In this scenario, Equation (19) has one real root and two nonreal complex conjugate roots for each temperature difference. The solid line (real root) in Figure 7 represents the simulated results obtained using Equations (1)-(19), whereas the dotted line represents the fitting results obtained from an experiment. 
For the experimental results, the wheel rotation is determined in revolutions per minute, whereas for the theoretical results, the wheel rotation is determined in revolutions per second (Hz). There exist 63 experiment points, and the fitting line is a cubic equation, which is represented as follows: $\Delta T=-0.0003 f^{3}+0.0105 f^{2}+0.0975 f$.

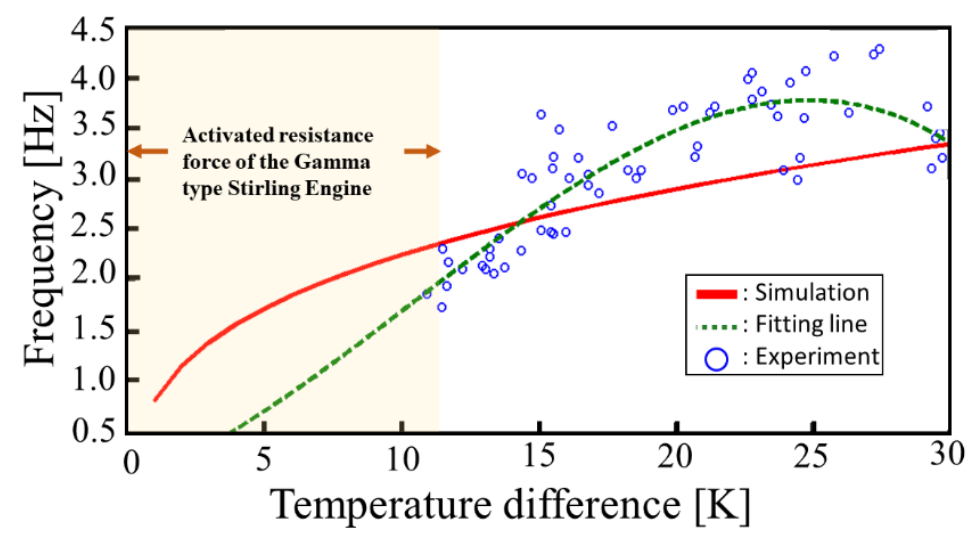

Figure 7. Relationship between the temperature difference of the Stirling engine and the frequency of the wheel. Small circles represent the experimental data, solid line the simulation data, and dotted line the fitting line with the cubic equation.

As displayed in Figure 7, the triggered temperature difference of the Stirling engine is at least $12 \mathrm{~K}$ because the engine must overcome the friction and mass of the mechanical system $\left(M_{1}, M_{2}, M_{s}, M_{c}\right.$, and $\left.M_{\text {wheel }}\right)$. The activated resistance force is $\left[M_{1}+\mu_{k}\left(M_{2}+M_{s}+M_{c}+M_{\text {wheel }}\right)\right] g=0.1731 \mathrm{~N}$. Furthermore, through Equation (10), the difference in the pressures at $293\left(P_{0}\right)$ and $305\left(P_{12}\right) \mathrm{K}$ is calculated to be $27.4 \mathrm{~Pa}$ for $\theta=0$. The pressure on the displacer is equal to $0.1743 \mathrm{~N}$.

The work system of the Stirling engine is divided into the mechanical, gas, and friction parts (Figure 8a). The work of the mechanical part comprises $W_{\text {dis }}, W_{\text {pis }}, W_{\text {shaft }}$, and $W_{\text {wheel }}$. The motion of the displacer and piston is vertical simple harmonic motion through wheel rotation. Therefore, the lines of $W_{\text {dis }}$ and $W_{\text {pis }}$ depend on the position functions of the displacer and piston. Because the Stirling engine works in a steady state, the angular velocity is independent of time. Therefore, $W_{\text {shaft }}$ is a constant volume. Moreover, there exist two holes in the first quadrant of the flywheel. Consequently, the moment of inertia depends on the phase angle (Figure $8 b$ ). The work of the gas contains $W_{p p}$ and $W_{p d}$. Both the lines displayed in Figure $8 c$ are sine functions. When $W_{p p}$ is a positive volume, the fluid in the engine outputs work to the piston; otherwise, the piston compresses the fluid in the engine. The displacer only moves the fluid in the air room and cannot compress or expand the fluid. Therefore, the volume of $W_{p d}$ is positive. Two peak volumes exist for $W_{p d}$. These peak volumes represent the displacer touching the clearance in the hot and cold areas (Figure $8 \mathrm{c}$ ). At the friction work part (Figure 8d), when $F_{\text {displacer }}$ and $F_{\text {piston }}$ drive the shaft rotation, the work of friction $\left(\Omega_{\text {shaft }}\right)$ reduces the mechanical work of gas expansion. $\Omega_{s p}$ and $\Omega_{s D R}$ are produced when the piston and displacer rod friction fluid (negative value). $\Omega_{S}$ is produced when the fluid is reflected from the cold plate inside friction the lateral surface of displacer (positive value, reverse direction). 


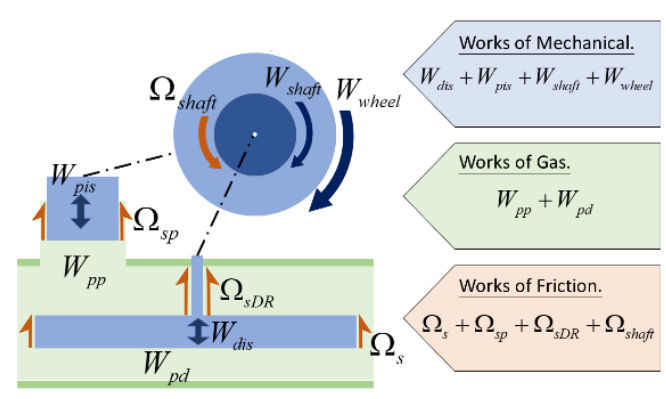

(a)

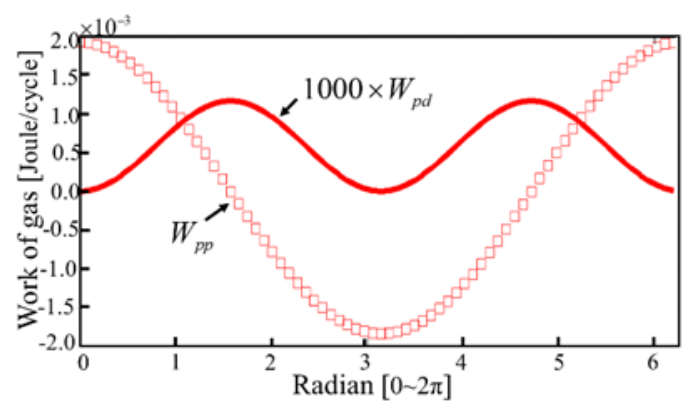

(c)

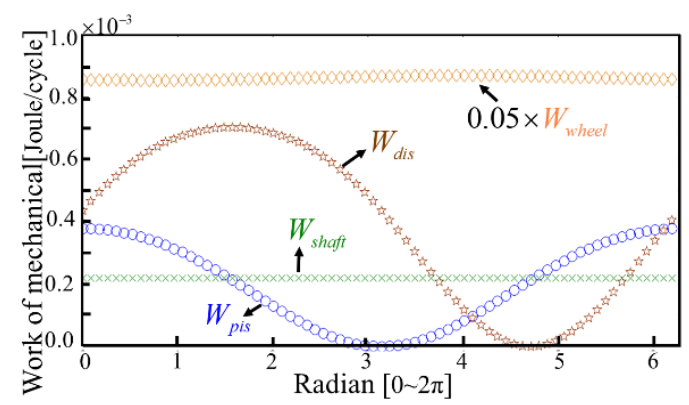

(b)

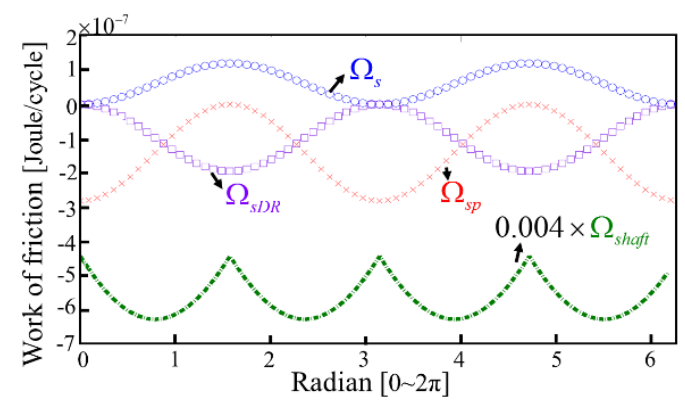

(d)

Figure 8. Distribution of work from the heat source in one cycle of the gamma-type Stirling engine. (a) Major components in the engine, (b) work values of the gas part, (c) work values of the mechanical part, and (d) work values of the friction part.

To compare the effect of the area of heated plate with the Stirling engine, a dimensionless length ratio is defined. The length ratio is equal to the diameter of the displacer divided by the diameter of the wheel $\left(D / 2 R_{w}\right)$. The length ratio is proportional to the heat flux of the air room if the gap between the displacer and displacer cylinder is fixed. Figure 9a displays the relationship between the length ratio, temperature difference, and frequency of the wheel. When the temperature of the hot plate is $30 \mathrm{~K}$ higher than that of the cold plate, the wheel rotation frequency equals $3.35 \mathrm{~Hz}$. However, when the length ratio is increased by six times, the rotation speed increases by 2.69 times. Figure $9 \mathrm{~b}$ illustrates power required $\left(W_{\text {wheel }}+W_{\text {dis }}+W_{\text {shaft }}+W_{\text {pis }}+W_{p d}+W_{p p}+\Omega_{s}+\Omega_{s p}+\Omega_{s D R}+\Omega_{\text {shaft }}\right)$ by the Stirling engine in the steady state. When the length ratio increases, the mass of the wheel increases. Therefore, the engine requires additional energy to push the wheel.

The aforementioned frequency (Figures 7-9) of the Stirling engine is simulated through Equations (25) and (26). The dielectric coefficient of acrylic $\left(\varepsilon_{a}\right)$ is 3.7, and the dielectric thickness $(h)$ is $1 \mu \mathrm{m}$. The energy and power produced can be calculated. As displayed in Figure 10a,b, different bias voltages $(26,44,53,61$, and $70 \mathrm{~V})$ are produced between the two plates of the capacitor. The variable capacitance produces power along the piston of the Stirling engine. As per the computational results, the energy harvester produces $6.2 \mathrm{~mJ}$ of energy per cycle per unit area at a bias voltage of $70 \mathrm{~V}$ and temperature difference of $30^{\circ} \mathrm{C}$. Thus, the engine produced $21 \mathrm{~mW}$ of energy per unit area. 


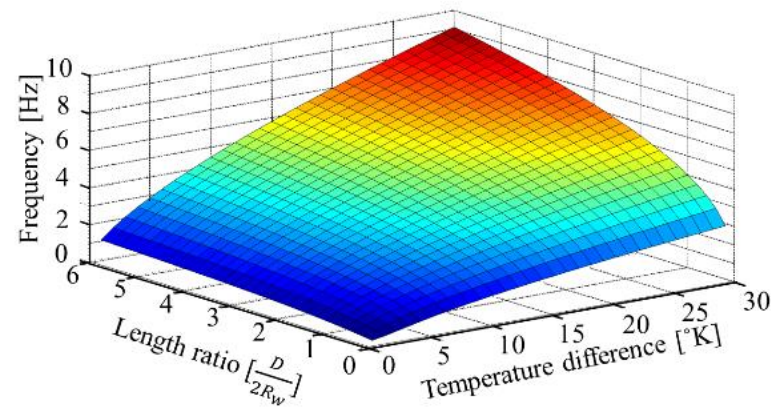

(a)

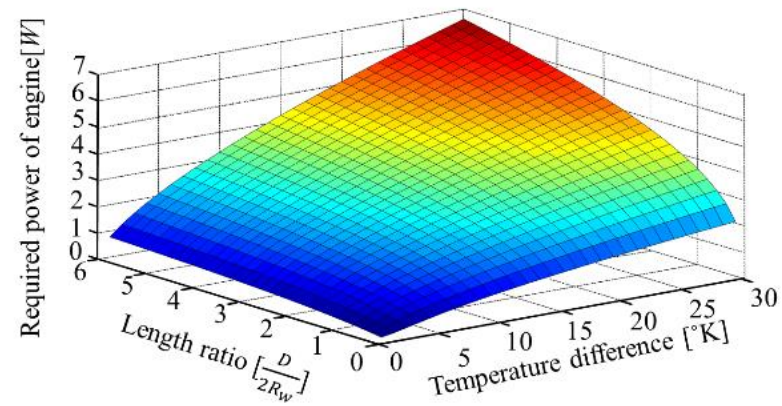

(b)

Figure 9. Relationship between the length ratio $\left(D / 2 R_{w}\right)$ and frequency of the wheel at various temperature differences. (a) Frequency of the wheel with different length ratios (0-6) at various temperature differences $(\Delta T=0-30 \mathrm{~K})$. (b) Required power of the engine with different length ratios $(0-6)$ at different temperature differences $(\Delta T=0-30 \mathrm{~K})$.

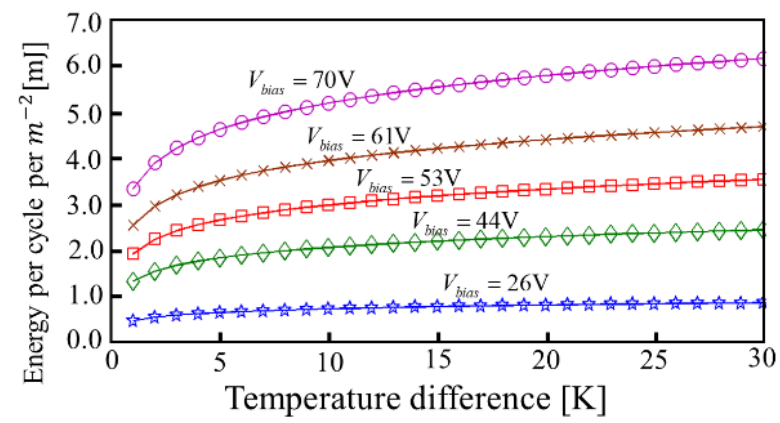

(a)

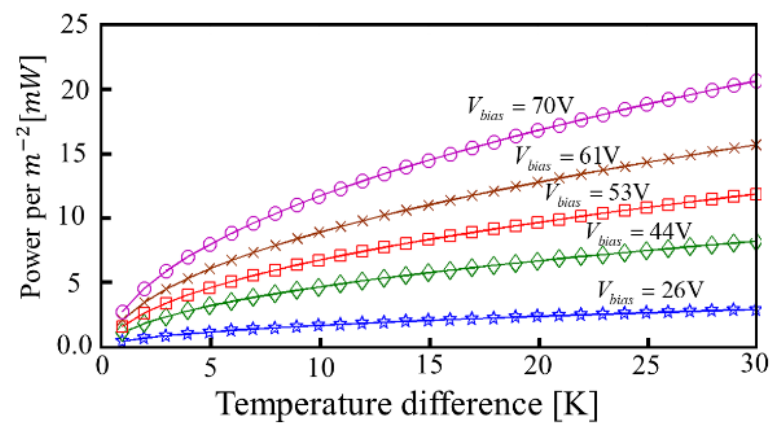

(b)

Figure 10. Results of the energy generated per unit area per unit rotating cycle at the wheel for various temperature differences. (a) The energy produced with the Stirling engine energy harvester at different bias voltages. (b) The power produced with the Stirling engine energy harvester at different bias voltages. 
The conversion efficiency of heat energy into electric power is calculated using the formula $\eta_{h e}=100(P / q)$. The conversion efficiency of engine power into electric power is calculated using the formula $\eta_{e e}=100(P / \eta)$. In this study, $\eta=1-\left(T_{4} / T_{1}\right), A_{\text {over }}=A_{D c}, h=1 \mu \mathrm{m}$, and $V_{b i a s}=70 \mathrm{~V}$. A dimensional number (ss) is delineated to adjust the size of the Stirling engine. For instance, an ss value of 2 indicates that the length, mass, and gap between the displacer and displacer cylinder of the Stirling engine become two times the dielectric thickness. The efficiency of the heat engine power $(\eta)$ is proportional to the temperature difference. However, the relationship between the frequency of the wheel and temperature is a concave curve. When $\Delta T>10 \mathrm{~K}$, the rate of increase decreases. Therefore, the conversion efficiency of engine power into electric power follows the trend of a convex curve (Figure 11a). Considering the dimensional efficiency, a large energy harvester is suitable for high temperature differences. For instance, $\eta_{h e}(s s=150)$ is twice $\eta_{h e}(s s=30)$ at $\Delta T=60-90 \mathrm{~K}$. In Figure 10 , each curve of $\eta_{e e}$ has a maximum value $\left[\eta_{e e, \max }(s s=30)\right.$ at $\Delta T=7 \mathrm{~K}, \eta_{e e, \max }(s s=60)$ at $\Delta T=18 \mathrm{~K}$, and $\eta_{e e, \max }(s s=90)$ at $\left.\Delta T=30 \mathrm{~K}\right]$, the corresponding temperature difference is the best temperature difference $\left(T_{b t}\right)$ for the conversion efficiency of heat energy into electric power. Thus, $\eta_{e e}$ exhibits positive growth for temperature differences below $T_{b t}$.

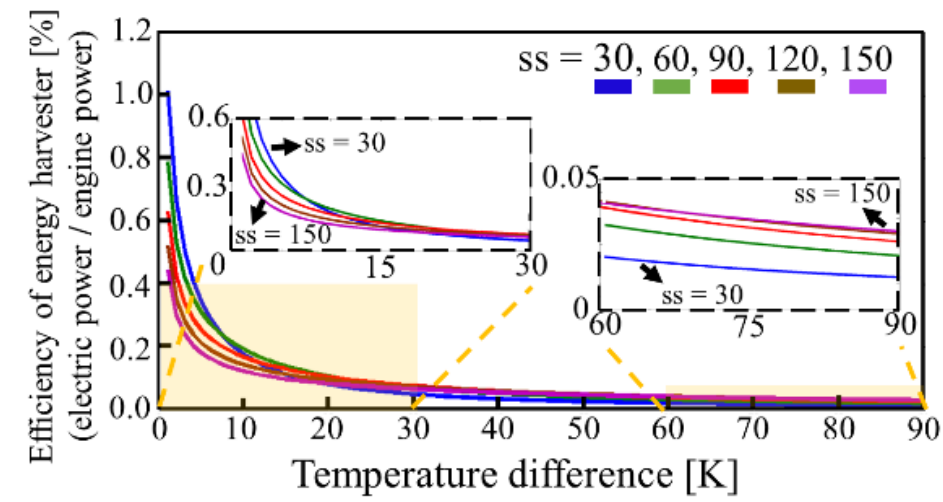

(a)

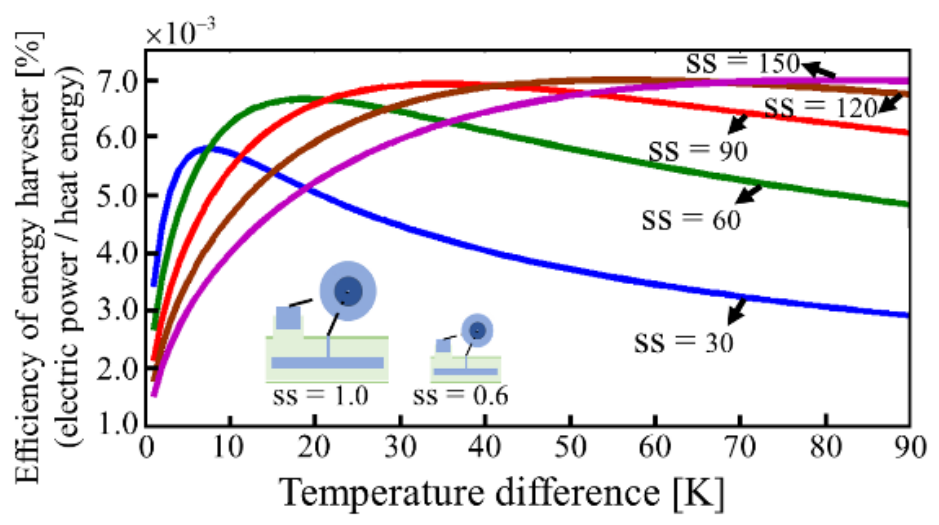

(b)

Figure 11. Results for the dimensional efficiency (dimensional number $=30,60,90,120$, and 150) of the Stirling engine energy harvester at various temperature differences. Conversion efficiency of (a) engine power into electric power for the Stirling engine energy harvester and (b) heat energy into electric power for the Stirling engine energy harvester.

\section{Conclusions}

In this study, a mathematical model that considers the conversion of heat energy to mechanical energy and the mechanical energy to electric energy is proposed and the relationship between the 
frequency and temperature difference is verified. The simulated results indicate that the frequency of the wheel is $3.35 \mathrm{~Hz}$ at $\Delta T=30 \mathrm{~K}(293-323 \mathrm{~K})$ and the triggered temperature difference of the Stirling engine is $12 \mathrm{~K}(293-305 \mathrm{~K})$. A small pressure difference exists between the hot and cold regions in the air room of the gamma Stirling engine $( \pm 0.1 \mathrm{~Pa}$ at $\Delta T=30 \mathrm{~K})$. When heat enters the work system of the Stirling engine, the energy can be divided into three parts: mechanical, air, and friction energy. The proportions of energy depend on the angular velocity of the engine $[\omega=2 \pi(3.35)]$. The rotation of the wheel, which involves mechanical work, requires the highest heat energy. Moreover, the ratio between the power of work and resistance of work $\left(D / 2 R_{w}\right)$ affects the frequency and moment of inertia. When the length ratio increases by six times, the rotation speed increases by 2.69 times. When a variable capacitor is applied to harvest energy at $V_{\text {bias }}=70 \mathrm{~V}$ and $\Delta T=30 \mathrm{~K}, 21 \mathrm{~mW}$ electric power is produced, which can be harvested and stored at room temperature. The optimized conversion efficiency of heat energy into electric power is obtained through the ss. Every size of the Stirling engine energy harvester has a best temperature difference range. It can provide power for low-power sensors to be used in remote mountains, rainforests, and deserts.

Funding: This research received no external funding.

Conflicts of Interest: The authors declare no conflict of interest.

\section{Appendix A}

Table A1. The coefficient of Equation (19).

\begin{tabular}{|c|c|c|}
\hline \multicolumn{3}{|c|}{$\Delta T=c_{1} f^{3}+c_{2} f^{2}+c_{3} f$} \\
\hline Coefficient & Function & Remark \\
\hline$c_{1}$ & $\begin{array}{c}\left|\frac{\pi^{2}}{2}\left[M_{1} L^{2} \int_{0}^{2 \pi} \sin ^{2} \theta d \theta+M_{2} L_{p}^{2} \int_{0}^{2 \pi} \sin \left(\theta-\frac{\pi}{2}\right) d \theta\right]\right|\left(R_{\text {con }}\right) \\
\left|+4 \pi^{3} \mu_{k} R_{c} L\left[M_{1} \int_{0}^{2 \pi} \cos \theta d \theta+M_{2} \int_{0}^{2 \pi} \cos \left(\theta-\frac{\pi}{2}\right) d \theta\right]\right|\left(R_{\text {con }}\right) \\
\left|+2 \pi^{2}\left(0.5 M_{\text {wheel }} R_{\text {wheel }}^{2}+M_{\text {wheel }}+R_{\text {new }}^{2}\right)\right|\left(R_{\text {con }}\right) \\
\left|+2 \pi^{2}\left(m_{s} R_{s}^{2}\right)\right|\left(R_{\text {con }}\right) \\
\left|+\pi^{2} M_{c} L_{c}^{2}\right|\left(R_{\text {con }}\right)\end{array}$ & $\begin{array}{l}\text { Kinetic energy of } M_{1} \text { and } M_{2} \text { systems. } \\
\text { Kinetic friction loss } M_{1} \text { and } \\
M_{2} \text { systems. } \\
\text { Kinetic energy of the } \\
\text { flywheel component. } \\
\text { Kinetic energy of the shaft component. } \\
\text { Kinetic energy of the } \\
\text { bearing component. }\end{array}$ \\
\hline$c_{2}$ & $\begin{array}{c}\left|L_{p} A_{p} \pi \int_{0}^{2 \pi} \frac{\left(a_{6}+a_{9}\right) \sin \theta+a_{7} \cos \theta \sin \theta}{a_{1}+a_{4}+a_{8}+\left(a_{2}+a_{5}\right) \cos \theta+a_{3} \cos \left(\theta+\frac{\pi}{2}\right)} \sin \left(\theta+\frac{\pi}{2}\right) d \theta\right|\left(R_{c o n}\right) \\
\mid-L\left\{\pi^{2} \cdot D \cdot l_{D} \cdot \int_{0}^{2 \pi} \sin \theta\left[\frac{\mu}{a}\left(-\frac{L}{2} \sin \theta\right) \ldots\right.\right. \\
\left.\left.\quad+\frac{2}{a}\left(-\frac{6 \mu L}{\pi \cdot D \cdot a^{3}}\left(A_{D c}+\frac{\pi \cdot D \cdot a}{2}\right)\right)\right] d \theta\right\} \mid\left(R_{c o n}\right) \\
\left|+L_{p}\left[\pi^{2} \cdot D_{p} \cdot l_{p} \frac{\mu}{2 r_{p} \ln \left(r_{p} / r_{p}+a_{p}\right)} \int_{0}^{2 \pi} \sin ^{2}\left(\theta+\frac{\pi}{2}\right) d \theta\right]\right|\left(R_{c o n}\right) \\
\left|+L\left[\pi^{2} \cdot r_{D R} \cdot l_{D R} \frac{\mu}{r_{D R} \ln \left(r_{D R} / r_{D R}+a_{D R}\right)} \int_{0}^{2 \pi} \sin ^{2} \theta d \theta\right]\right|\left(R_{c o n}\right) \\
\left|\frac{6 \mu L}{\pi D a^{3}}\left(A_{D c}+\frac{\pi D a}{2}\right)\left(L \cdot A \cdot l_{D} \cdot \pi\right) \int_{0}^{2 \pi}(\sin \theta)^{2} d \theta\right|\left(R_{c o n}\right)\end{array}$ & $\begin{array}{l}\text { Moving-boundary work of piston. } \\
\text { Friction loss from the viscous drags in } \\
\text { the displacer. } \\
\text { Friction loss from the viscous drags in } \\
\text { the piston. } \\
\text { Friction loss from the viscous drags in } \\
\text { the rod. } \\
\text { Moving-boundary work of displacer. }\end{array}$ \\
\hline$c_{3}$ & $\begin{array}{c}\left|-\frac{L_{p}}{2} A_{p} \int_{0}^{2 \pi} \frac{M}{a_{1}+a_{4}+a_{8}+\left(a_{2}+a_{5}\right) \cos \theta+a_{3} \cos \left(\theta+\frac{\pi}{2}\right)} \sin \left(\theta+\frac{\pi}{2}\right) d \theta\right|\left(R_{\text {con }}\right) \\
\left|+\alpha \pi \mu_{k} R_{c} L\left[M_{1} \int_{0}^{2 \pi} \sin \theta d \theta+M_{2} \int_{0}^{2 \pi} \sin \left(\theta-\frac{\pi}{2}\right) d \theta\right]\right|\left(R_{\text {con }}\right) \\
\left|+g\left[\left(M_{1} \cdot z\right)+\left(M_{2} \cdot z_{p}\right)+\left(M_{\text {wheel }} \cdot Z_{\text {wheel }}\right)\right]\right|\left(R_{\text {con }}\right)\end{array}$ & $\begin{array}{l}\text { Moving-boundary work of piston. } \\
\text { Kinetic friction loss } M_{1} \text { and } \\
\qquad M_{2} \text { systems. } \\
\text { Potential energy of the } M_{1}, M_{2} \\
\text { systems, and flywheel component. }\end{array}$ \\
\hline $\mathrm{R}_{\text {con }}$ & $\frac{\Delta z_{\text {Hot }}}{k_{\text {Hot }} A}+\frac{\Delta z_{\text {Air }}}{k_{\text {Air }} A}+\frac{\Delta z_{\text {Cold }}}{k_{\text {Cold }} A}$ & $\begin{array}{l}\text { Thermal resistance in series of the } \\
\text { Stirling engine components. }\end{array}$ \\
\hline
\end{tabular}


Table A2. The coefficient of Equation (10).

\begin{tabular}{cc}
\hline $\mathrm{a}_{1}$ & $\frac{V_{p d}+V_{c d}+0.5\left(A_{D c} L+A_{p} L_{p}\right)}{R T_{c a}}$ \\
\hline$a_{2}$ & $\frac{-0.5 A_{D c} L}{R T_{c a}}$ \\
\hline$a_{3}$ & $\frac{0.5 A_{p} L_{p}}{R T_{c a}}$ \\
\hline$a_{4}$ & $\frac{V_{h d}+0.5 A_{D c} L}{R T_{h a}}$ \\
\hline$a_{5}$ & $\frac{0.5 A_{D c} L}{R T_{h a}}$ \\
\hline$a_{6}$ & $c_{0} l_{D} \frac{V_{h d}+0.5 A_{D c} L}{R T_{h a}}$ \\
\hline$a_{7}$ & $c_{0} l_{D} \frac{0.5 A_{D c} L}{R T_{h a}}$ \\
\hline$a_{8}$ & $2 l_{D} \frac{A_{D c}-A}{R\left(T_{c a}+T_{h a}\right)}$ \\
\hline$a_{9}$ & $c_{0} l_{D} \frac{\left(A_{D c}-A\right) l_{D}}{R\left(T_{c a}+T_{h a}\right)}$ \\
\hline
\end{tabular}

Table A3. Nomenclature and dimensions of Gamma-type Stirling engine components.

\begin{tabular}{|c|c|c|c|}
\hline Symbol & Description & Dimensions & Unit \\
\hline$A_{D c}$ & Air room cross-sectional area & & $\mathrm{m}^{2}$ \\
\hline$A_{p}$ & Piston cross-sectional area & & $\mathrm{m}^{2}$ \\
\hline$A_{\text {over }}$ & The maximum overlap area between two electric plate & & $\mathrm{m}^{2}$ \\
\hline$a$ & Gap between displacer and displacer cylinder & $4.5 \times 10^{-3}$ & M \\
\hline$a_{p}$ & Gap between piston and cylinder & $1 \times 10^{-4}$ & M \\
\hline$a_{D R}$ & Gap between displacer rod and bushing & $1 \times 10^{-4}$ & M \\
\hline$C$ & Variable capacitor & & $\mathrm{F}$ \\
\hline$C_{0}$ & The maximum capacitance & & $\mathrm{F}$ \\
\hline$D$ & Displacer diameter & $9 \times 10^{-2}$ & M \\
\hline$D_{D R}$ & Displacer rod dimeter & $3.5 \times 10^{-3}$ & M \\
\hline$D_{p}$ & Piston dimeter & $1.1 \times 10^{-2}$ & M \\
\hline E & Energy of Stirling engine harvester output per cycle & & $\mathrm{J}$ \\
\hline$F_{s}$ & Shear force on displacer lateral surface & & $\mathrm{N}$ \\
\hline$F_{s p}$ & Shear force on displacer rod lateral surface & & $\mathrm{N}$ \\
\hline$F_{S D R}$ & Shear force on piston lateral surface & & $\mathrm{N}$ \\
\hline$f$ & Frequency of rotating wheel & & $\mathrm{s}^{-1}$ \\
\hline$h$ & Dielectric thickness & $1 \times 10^{-6}$ & M \\
\hline$k_{\text {Hot }}$ & Thermal conductivity of hot plate & 202 & $\mathrm{Wm}^{-1} \mathrm{~K}^{-1}$ \\
\hline$k_{\text {Cold }}$ & Thermal conductivity of cold plate & 202 & $\mathrm{Wm}^{-1} \mathrm{~K}^{-1}$ \\
\hline$k_{\text {Air }}$ & Thermal conductivity of air room & 1.44 & $\mathrm{Wm}^{-1} \mathrm{~K}^{-1}$ \\
\hline$k_{\text {die }}$ & Thin film dielectric constant & 3.7 & \\
\hline$L$ & Displacer stroke & $7 \times 10^{-3}$ & M \\
\hline$L_{p}$ & Piston stroke & $1.3 \times 10^{-2}$ & M \\
\hline$l_{c}$ & Length of clearance in the cold end of displacer cylinder & $2.5 \times 10^{-3}$ & M \\
\hline$l_{h}$ & Length of clearance in the hot end of displacer cylinder & $2.5 \times 10^{-3}$ & M \\
\hline$l_{D}$ & Displacer length & $8 \times 10^{-3}$ & M \\
\hline$l_{D R}$ & Length of the bushing of displacer rod & $3 \times 10^{-2}$ & M \\
\hline$M$ & Total mass or air room & & $\mathrm{kg}$ \\
\hline
\end{tabular}


Table A3. Cont.

\begin{tabular}{|c|c|c|c|}
\hline Symbol & Description & Dimensions & Unit \\
\hline$M_{\text {wheel }}$ & Mass of flywheel & $2.64 \times 10^{-2}$ & $\mathrm{~kg}$ \\
\hline$M_{c}$ & Mass of bearing & $2 \times 10^{-3}$ & $\mathrm{~kg}$ \\
\hline$M_{s}$ & Mass of shaft & $7.7 \times 10^{-3}$ & $\mathrm{~kg}$ \\
\hline$M_{1}$ & Mass of displacement system & $5.5 \times 10^{-3}$ & $\mathrm{~kg}$ \\
\hline$M_{2}$ & Mass of piston system & $4.4 \times 10^{-3}$ & $\mathrm{~kg}$ \\
\hline$P$ & Power of Stirling engine harvest output per cycle & & $\mathrm{W}$ \\
\hline$p$ & Pressure & & $\mathrm{Pa}$ \\
\hline$p_{c}$ & Pressure of the cold region & & $\mathrm{Pa}$ \\
\hline$P_{h}$ & Pressure of the hot region & & $\mathrm{Pa}$ \\
\hline$P_{12}$ & Pressure in the air room at $305 \mathrm{~K}$ & & $\mathrm{~Pa}$ \\
\hline$P_{0}$ & Pressure in the air room at $293 \mathrm{~K}$ & & $\mathrm{~Pa}$ \\
\hline$Q_{v}$ & Volume flow rate in displacer annulus & & $\mathrm{m}^{3} \mathrm{~s}^{-1}$ \\
\hline$Q_{c}$ & Charge on the variable capacitor & & $\mathrm{C}$ \\
\hline$q$ & Heat transfer rate & & W \\
\hline$R$ & Resistive load & & $\Omega$ \\
\hline$R_{\text {new }}$ & Distance between center of flywheel and mass of center point & & M \\
\hline$R_{c}$ & Radius of bearing & $1.5 \times 10^{-3}$ & M \\
\hline$R_{S}$ & Radius of shaft & $7.5 \times 10^{-3}$ & M \\
\hline$R_{w}$ & Radius of wheel & & $\mathrm{M}$ \\
\hline ss & Dimensional number & & \\
\hline$T_{1}$ & Stirling engine hot-end temperature & & K \\
\hline$T_{4}$ & Stirling engine cold-end temperature & 293 & K \\
\hline$T_{b t}$ & $\begin{array}{l}\text { The best temperature differences for efficiency of heat engine } \\
\text { to electric power }\end{array}$ & & K \\
\hline $\mathrm{T}_{\text {per }}$ & Period & & $\mathrm{s}$ \\
\hline$t$ & time & & $\mathrm{s}$ \\
\hline$U_{z}$ & Velocity of displacer & & $\mathrm{ms}^{-1}$ \\
\hline$U_{z p}$ & Velocity of piston & & $\mathrm{ms}^{-1}$ \\
\hline$V_{a u}$ & $\begin{array}{l}\text { Volume of the annulus between the displacer and } \\
\text { displace cylinder }\end{array}$ & & $\mathrm{m}^{3}$ \\
\hline$V_{c d}$ & Clearance in the cold end of the displace cylinder & & $\mathrm{m}^{3}$ \\
\hline$V_{h d}$ & Clearance in the hot end of the displace cylinder & & $\mathrm{m}^{3}$ \\
\hline$V_{c D}$ & $\begin{array}{l}\text { Volume swept by the displacer in the cold end of the } \\
\text { displace cylinder }\end{array}$ & & $\mathrm{m}^{3}$ \\
\hline$V_{h D}$ & $\begin{array}{l}\text { Volume swept by the displacer in the hot end of the } \\
\text { displace cylinder }\end{array}$ & & $\mathrm{m}^{3}$ \\
\hline$V_{p}$ & Volume swept by the piston & & $\mathrm{m}^{3}$ \\
\hline$V_{p d}$ & Clearance in the power cylinder & & $\mathrm{m}^{3}$ \\
\hline$V_{\text {tan }}$ & Tangential velocity of shaft & & $\mathrm{m}^{3}$ \\
\hline$V_{\text {bias }}$ & Bias voltage & & V \\
\hline$W_{s}$ & Shear work on the displacer lateral surface & & $\mathrm{J}$ \\
\hline$W_{S D R}$ & Shear work on the displacer rod & & $\mathrm{J}$ \\
\hline$W_{s p}$ & Shear work on the piston lateral surface & & $\mathrm{J}$ \\
\hline$W_{\text {eng }}$ & Stirling engine work & & $\mathrm{J}$ \\
\hline
\end{tabular}


Table A3. Cont.

\begin{tabular}{|c|c|c|c|}
\hline Symbol & Description & Dimensions & Unit \\
\hline$W_{\text {gas }}$ & Work of gas & & $\mathrm{J}$ \\
\hline$W_{\text {mech }}$ & Work of mechanical & & $\mathrm{J}$ \\
\hline$W_{\text {loss }}$ & Work of friction loss & & $\mathrm{J}$ \\
\hline$W_{p p}$ & Moving-boundary work by piston per cycle & & $\mathrm{J}$ \\
\hline$W_{p d}$ & Moving-boundary work by displacer per cycle & & $\mathrm{J}$ \\
\hline$W_{\text {wheel }}$ & Work of flywheel & & $\mathrm{J}$ \\
\hline$W_{\text {shaft }}$ & Work of shaft & & $\mathrm{J}$ \\
\hline$W_{d i s}$ & Work of displacer system & & $\mathrm{J}$ \\
\hline$W_{p i s}$ & Work of piston system & & $\mathrm{J}$ \\
\hline$Z_{\text {wheel }}$ & Vertical position of mass center point of wheel & & \\
\hline$z$ & Vertical position of the displacer & & M \\
\hline$z_{p}$ & Vertical position of the piston & & M \\
\hline$\Delta z_{\text {Hot }}$ & Thickness of hot plate of Stirling engine & $2 \times 10^{-3}$ & M \\
\hline$\Delta z_{\text {Cold }}$ & Thickness of cold plate of Stirling engine & $2 \times 10^{-3}$ & M \\
\hline$\Delta z_{\text {Air }}$ & Thickness of air room & $2 \times 10^{-2}$ & M \\
\hline$\alpha$ & Angular acceleration of wheel & & \\
\hline$\theta$ & Angle of Stirling engine shaft & & \\
\hline$\omega$ & Angular velocity & & $\mathrm{rad} / \mathrm{s}$ \\
\hline$\mu$ & Dynamic viscosity or air & $1.8 \times 10^{-5}$ & Pa.s \\
\hline$\mu_{k}$ & Coefficient of kinetic friction & 0.17 & \\
\hline$\Omega_{s}$ & Work of friction loss in displacer per cycle & & $\mathrm{J}$ \\
\hline$\Omega_{s p}$ & Work of friction loss in piston per cycle & & $\mathrm{J}$ \\
\hline$\Omega_{S D R}$ & Work of friction loss in displacer rod per cycle & & $\mathrm{J}$ \\
\hline$\Omega_{\text {shaft }}$ & Work of friction with a cycle & & $\mathrm{J}$ \\
\hline$\varepsilon_{0}$ & Vacuum permittivity & $\underset{10^{-12}}{8.854 \ldots \times}$ & $\mathrm{F} / \mathrm{m}$ \\
\hline$\tau$ & Shear stresses on the lateral surface of displacer & & $\mathrm{N} / \mathrm{A}$ \\
\hline$\tau_{p}$ & Shear stresses on the lateral surface of piston & & $\mathrm{N} / \mathrm{A}$ \\
\hline$\tau_{D R}$ & Shear stresses on the lateral surface of displacer rod & & $\mathrm{N} / \mathrm{A}$ \\
\hline$\tau_{\text {shaft }}$ & Load from $\mathrm{m}_{1}$ and $\mathrm{m}_{2}$ & & $\mathrm{~N}$ \\
\hline$\eta$ & Efficiency of engine power & & $\%$ \\
\hline$\eta_{h e}$ & Efficiency of heat energy to electric power & & $\%$ \\
\hline$\eta_{e e}$ & Efficiency of engine power to electric power & & $\%$ \\
\hline
\end{tabular}

\section{References}

1. Tartakovsky, L.; Sheintuch, M. Fuel reforming in internal combustion engines. Prog. Energy Combus. Sci. 2018, 67, 88-114. [CrossRef]

2. LeBlanc, S.; Yee, S.K.; Scullin, M.L.; Dames, C.; Goodson, K.E. Material and manufacturing cost considerations for thermoelectrics. Renew. Sustain. Energy Rev. 2014, 32, 313-327. [CrossRef]

3. Organ, A.J. Stirling's air engine-a thermodynamic appreciation. Inst. Mech. Eng. 2000, 14, 511. [CrossRef]

4. Egas, J.; Clucas, D.M. Stirling Engine Configuration Selection. Energies 2018, 11, 584. [CrossRef]

5. Kongtragool, B.; Wongwises, S. Performance of low-temperature differential Stirling engines. Renew. Energy 2007, 32, 547-566. [CrossRef]

6. Chen, W.-L.; Yang, Y.-C.; Salazar, J.L. A CFD parametric study on the performance of a low-temperature-differential $\gamma$-type Stirling engine. Energy Convers. Manag. 2015, 106, 635-643. [CrossRef] 
7. Robson, A.; Grassie, T.; Kubie, J. Modelling of a low-temperature differential Stirling engine. Proc. Inst. Mech. Eng. Part C J. Mech. Eng. Sci. 2016, 221, 927-943. [CrossRef]

8. Kim, Y.M.; Chun, W.G.; Chen, K. Thermal-Flow Analysis of a Simple LTD (Low-Temperature-Differential) Heat Engine. Energies 2017, 10, 567. [CrossRef]

9. Tan, Y.S.; Dong, Y.; Wang, X.H. Review of MEMS Electromagnetic Vibration Energy Harvester. J. Microelectromech. Syst. 2017, 26, 1-16. [CrossRef]

10. Invernizzi, F.; Dulio, S.; Patrini, M.; Guizzetti, G.; Mustarelli, P. Energy harvesting from human motion: Materials and techniques. Chem. Soc. Rev. 2016, 45, 5455-5473. [CrossRef] [PubMed]

11. Wei, C.F.; Jing, X.J. A comprehensive review on vibration energy harvesting: Modelling and realization. Renew. Sustain. Energy Rev. 2017, 74, 1-18. [CrossRef]

12. Peano, F.; Tambosso, T. Design and optimization of a MEMS electret-based capacitive energy scavenger. J. Microelectromech. Syst. 2005, 14, 429-435. [CrossRef]

13. Meninger, S.; Mur-Miranda, J.O.; Amirtharajah, R.; Chandrakasan, A.P.; Lang, J.H. Vibration-to-electric energy conversion. IEEE Trans. Very Large Scale Integr. (VLSI) Syst. 2001, 9, 64-76. [CrossRef]

14. Yen, B.C.; Lang, J.H. A variable-capacitance vibration-to-electric energy harvester. IEEE Trans. Circuits Syst. I Regul. Pap. 2006, 53, 288-295. [CrossRef]

15. Moon, J.K.; Jeong, J.; Lee, D.; Pak, H.K. Electrical power generation by mechanically modulating electrical double layers. Nat. Commun. 2013, 4, 1487. [CrossRef]

16. Hsu, T.H.; Manakasettharn, S.; Taylor, J.A.; Krupenkin, T. Bubbler: A Novel Ultra-High Power Density Energy Harvesting Method Based on Reverse Electrowetting. Sci. Rep. 2015, 5, 16537. [CrossRef]

17. Green, P.L.; Papatheou, E.; Sims, N.D. Energy harvesting from human motion and bridge vibrations: An evaluation of current nonlinear energy harvesting solutions. J. Intell. Mater. Syst. Struct. 2013, 24, 1494-1505. [CrossRef]

18. Cantero, D.; Hester, D.; Brownjohn, J. Evolution of bridge frequencies and modes of vibration during truck passage. Eng. Struct. 2017, 152, 452-464. [CrossRef]

19. Uematsu, A.; Inoue, K.; Hobara, H.; Kobayashi, H.; Iwamoto, Y.; Hortobagyi, T.; Suzuki, S. Preferred step frequency minimizes veering during natural human walking. Neurosci. Lett. 2011, 505, 291-293. [CrossRef] [PubMed]

20. Khan, F.U.; Iqbal, M. Electromagnetic-based bridge energy harvester using traffic-induced bridge's vibrations and ambient wind. In Proceedings of the 2016 International Conference on Intelligent Systems Engineering (ICISE), Islamabad, Pakistan, 15-17 January 2016; pp. 380-385.

21. Boisseau, S.; Despesse, G.; Ahmed, B. Electrostatic Conversion for Vibration Energy Harvesting. In Small-Scale Energy Harvesting; IntechOpen: London, UK, 2012.

22. Li, J.-F.; Lin, Y.-S.; Lin, C.-H.; Chen, K.-C. Three-Parameter Modeling of Nonlinear Capacity Fade for Lithium-Ion Batteries at Various Cycling Conditions. J. Electrochem. Soc. 2017, 164, A2767-A2776. [CrossRef]

23. Tavakolpour-Saleh, A.R.; Zare, S.H.; Bahreman, H. A novel active free piston Stirling engine: Modeling, development, and experiment. Appl. Energy 2017, 199, 400-415. [CrossRef]

24. Li, T.; Tang, D.W.; Li, Z.G.; Du, J.L.; Zhou, T.; Jia, Y. Development and test of a Stirling engine driven by waste gases for the micro-CHP system. Appl. Therm. Eng. 2012, 33, 119-123. [CrossRef]

25. Ulloa, C.; Eguia, P.; Miguez, J.L.; Porteiro, J.; Pousada-Carballo, J.M.; Cacabelos, A. Feasibility of using a Stirling engine-based micro-CHP to provide heat and electricity to a recreational sailing boat in different European ports. Appl. Therm. Eng. 2013, 59, 414-424. [CrossRef]

26. Mancini, T.; Heller, P.; Butler, B.; Osborn, B.; Schiel, W.; Goldberg, V.; Buck, R.; Diver, R.; Andraka, C.; Moreno, J. Dish-Stirling systems: An overview of development and status. J. Sol. Energy Eng. Trans. ASME 2003, 125, 135-151. [CrossRef]

27. Holman, J. Heat Transfer, 10th ed.; McGraw-Hill: New York, NY, USA, 2010.

28. Krupenkin, T.; Taylor, J.A. Reverse electrowetting as a new approach to high-power energy harvesting. Nat. Commun. 2011, 2, 448. [CrossRef]

(C) 2019 by the author. Licensee MDPI, Basel, Switzerland. This article is an open access article distributed under the terms and conditions of the Creative Commons Attribution (CC BY) license (http:/ / creativecommons.org/licenses/by/4.0/). 